Published in final edited form as:

Int J Eat Disord. 2020 January ; 53(1): 20-30. doi:10.1002/eat.23167.

\title{
Examining Sex as a Predictor and Moderator of Treatment Outcomes for Binge-Eating Disorder: Analysis of Aggregated Randomized Controlled Trials
}

\author{
Janet A. Lydecker, Ph.D. ${ }^{1}$, Ralitza Gueorguieva, Ph.D. ${ }^{1,2}$, Robin Masheb, Ph.D. ${ }^{1,3}$, Marney A. \\ White, Ph.D., M.S. ${ }^{1,4}$, Carlos M. Grilo, Ph.D. ${ }^{1,5}$ \\ ${ }^{1}$ Department of Psychiatry, Yale School of Medicine, New Haven, CT \\ ${ }^{2}$ Department of Biostatistics, Yale School of Public Health, New Haven, CT \\ ${ }^{3}$ PRIME HSR\&D Center of Innovation (COIN), VA Connecticut Healthcare System, West Haven, \\ CT \\ ${ }^{4}$ Department of Social and Behavioral Sciences, Yale School of Public Health, New Haven, CT \\ ${ }^{5}$ Department of Psychology, Yale University, New Haven, CT
}

\begin{abstract}
Background: This study examined whether sex predicted and/or moderated treatment outcomes among men and women who participated in binge-eating disorder (BED) randomized controlled trials (RCTs).

Methods: Data were aggregated from RCTs performed at one medical center. RCTs tested cognitive-behavioral therapy, behavioral weight loss, multi-modal treatment, and/or control conditions. Participants were 660 adults, both men $(n=170)$ and women $(n=490)$, with DSM-IVdefined BED. Doctoral-level research-clinicians assessed participants using structured interviews and established self-report measures of eating-disorder psychopathology and depression, and measured height and weight. Assessments occurred at baseline, throughout treatment, and at posttreatment.
\end{abstract}

Results: Sex was not a significant moderator of any treatment outcomes. Mixed models revealed sex had a main effect: men had lower eating-disorder psychopathology and lost more weight than women over the course of treatment.

Conclusions: Both epidemiological and RCT studies report disparities in treatment-seeking between men and women with BED. Despite this, men have comparable or better treatment

Correspondence should be addressed to Carlos M. Grilo, Ph.D., Yale School of Medicine, 301 Cedar Street, New Haven, CT 06519. carlos.grilo@yale.edu.

Potential conflicts of interest: The authors (Lydecker, Gueorguieva, Masheb, White, Grilo) report no conflicts of interest. Drs. Grilo and Gueorguieva report several broader interests which did not influence this research or paper.

Dr. Grilo's broader interests include: Consultant to Sunovion and Weight Watchers; Honoraria for lectures, CME activities, and presentations at scientific conferences; and Royalties from Guilford Press and Taylor \& Francis Publishers for academic books. Dr. Gueorguieva discloses consulting for Palo Alto Health Sciences, Mathematica Policy Research and Knopp Biosciences, a provisional patent submission by Yale University: Chekroud, AM., Gueorguieva, R., \& Krystal, JH. "Treatment Selection for Major Depressive Disorder" [filing date $3^{\text {rd }}$ June 2016, USPTO docket number Y0087.70116US00], and Royalties from Taylor \& Francis for an academic book. 
outcomes compared to women, including significantly greater weight loss. Thus, disseminating evidence-based BED treatments is promising for both men and women. Additional research is necessary, however, to understand treatment effects-including other predictors and moderators of outcomes—across diverse providers, treatment settings, and patient groups.

\section{Keywords}

sex; gender; binge-eating disorder; treatment; psychotherapy; cognitive-behavioral therapy; behavioral weight loss

\section{Introduction}

Binge-eating disorder (BED) is characterized by recurrent binge-eating episodes (i.e., eating an unusually large amount of food and experiencing loss of control while eating) without the compensatory behaviors that define bulimia nervosa (American Psychiatric Association, 2013). BED is the most prevalent formal eating disorder (Udo \& Grilo, 2018) and is associated with significantly elevated risk for psychiatric and medical comorbidity (Udo \& Grilo, 2019). The female-to-male ratio for individuals with BED, roughly 3:1, is much lower than for anorexia nervosa and bulimia nervosa (Marques et al., 2011; Udo \& Grilo, 2018). Importantly, men and women with BED experience similar levels of clinical impairment (Marques et al., 2011; Striegel, Bedrosian, Wang, \& Schwartz, 2012), yet men with BED seek treatment much less often than women with BED (Coffino, Udo, \& Grilo, 2019; Marques et al., 2011), and are substantially underrepresented in RCTs for BED (National Institues of Health, 2018).

There is evidence for specific psychological (Grilo, 2017b), pharmacological (Reas \& Grilo, 2015), and combination or "multi-modal" (Grilo, Reas, \& Mitchell, 2016) treatments for BED, yet only $45-54 \%$ of patients are abstinent from binge eating post-treatment (Hilbert et al., 2019). Thus, it is important to identify patient characteristics that are associated with better or worse outcomes (predictors), or that might signal for whom specific treatments may be more beneficial (moderators) (Kraemer, Wilson, Fairburn, \& Agras, 2002). Information about predictors and moderators could assist providers in making recommendations around the selection of possible treatments (Grilo, 2017b; Wilson, Grilo, \& Vitousek, 2007).

As most treatment trials for BED have been underpowered to allow for examination of whether sex predicts or moderates outcomes, one approach is to aggregate data across trials that used similar methods. Shingleton et al (2015) pooled data from 11 treatment studies (across nine research sites) that tested psychosocial treatments to yield male $(15.7 \% ; n=208)$ and female $(84.3 \% ; n=1117)$ study groups and found that sex did not predict or moderate outcomes. Findings from the Shingleton et al (2015) study make an important contribution to our understanding of BED treatment but require extension for several reasons, including: (a) studies within the pooled data used similar, but methodologically different, assessment measures for determining BED diagnosis and characterizing eating-disorder psychopathology; (b) sites contributed data with different proportions of male and female participants, perhaps reflecting differences in recruitment, inclusion and exclusion criteria, screening methods, and assessment procedures; (c) only participants who received 
psychological treatments were included (i.e., participants in control conditions were excluded from analyses); and (d) non-psychological interventions, including pharmacotherapy and combination treatments, were not included in pooled data, thereby severely limiting generalizability of findings. Thus, additional research is needed to evaluate sex differences in treatment outcomes among men and women with BED.

The current study examined differences in treatment outcomes between men and women in a large sample of adults with BED enrolled in treatment studies at one academic medical center. The current study's test of sex as a potential predictor and/or moderator was a secondary analysis of aggregated data from these controlled treatment trials. Because we did not know a priori whether sex would be a predictor or a moderator, and because predictors and moderators can both have unique clinical implications (Kraemer et al., 2002), we tested both in the current study. The current study examined sex as a potential predictor to contribute information about whether men or women differ on treatment outcomes, which can be clinically useful in helping patients understand the potential benefit of treatments. We also examined sex as a potential moderator to contribute information about whether outcomes of different treatments differed for men and women, which can be clinically useful in helping clinicians decide which treatments to recommend to their patients. Specifically, we examined key BED treatment outcomes: binge-eating episodes both dimensionally (frequency) and categorically (remission), weight both dimensionally (percent loss) and categorically (attainment of 5\% loss), associated eating-disorder psychopathology, and depression. Categorical weight loss was defined at the 5\% threshold because of established associations of this amount of weight loss with clinical benefits (Goldstein, 1992).

Data for current analyses were aggregated from randomized controlled trials (RCTs) for BED at one academic medical center. The RCTs tested cognitive-behavioral therapy (CBT), behavioral weight loss (BWL), multi-modal treatments, and/or control conditions. All participants were assessed for eligibility by doctoral-level research-clinicians using an interview-based evaluation of binge eating and eating-disorder psychopathology, completed similar assessment batteries, and had height and weight measured at similar repeated time points.

\section{Methods}

\section{Participants}

Participants ( $N=660)$ were patients in RCTs that tested pharmacological and psychological treatments for BED at a medical-school setting in the northeastern United States (Grilo, 2017a; Grilo \& Masheb, 2005; Grilo, Masheb, \& Salant, 2005; Grilo et al., 2014; Grilo, Masheb, \& Wilson, 2005; Grilo, Masheb, Wilson, Gueorguieva, \& White, 2011; Grilo, White, Gueorguieva, Barnes, \& Masheb, 2013). Three of these RCTs (Grilo \& Masheb, 2005; Grilo, Masheb, \& Salant, 2005; Grilo, Masheb, \& Wilson, 2005) provided cognitivebehavioral therapy data for the analyses previously conducted by Shingleton et al (2015). Participants were 18-65 years old and met full DSM-IV (American Psychiatric Association, $2004)$ criteria for BED. Of note, $D S M-I V B E D$ research criteria are more stringent than diagnostic criteria for BED in the DSM-5 (American Psychiatric Association, 2013); thus, all participants who met $D S M-I V$ criteria would also meet $D S M-5$ criteria for BED. 
Participants were excluded if they were receiving concurrent treatment (pharmacological or behavioral) for eating/weight concerns, had medical conditions that influenced eating/ weight, were taking medications that could influence eating/weight, had a severe mental illness that could interfere with clinical assessment or require alternative treatment (e.g., psychosis, acute suicidality), or were pregnant.

Overall, 170 men (25.76\%) and 490 women (74.24\%) were included in current analyses. The average age of women in the current study was 45.64 ( $S D=9.70)$ and the average age of men was 47.43 ( $S D=9.01)$. Overall, $70.7 \%$ of women were White $(n=345)$ and $79.3 \%$ of men were White $(n=134) ; 19.1 \%$ of women were Black $(n=93)$ and $11.8 \%$ of men were Black $(n=20) ; 5.7 \%$ of women were Hispanic $(n=28)$ and $6.5 \%$ of men were Hispanic $(n=11)$. Among women, $17.7 \%(n=86)$ had a high school education, $33.7 \%(n=164)$ had some college education or an associate's degree, and $48.7 \%(n=237)$ had a college degree. Among men, 30 (17.9\%) had a high school education, 60 (35.7\%) had some college education or an associate's degree, and $78(46.4 \%)$ had a college degree.

The Yale institutional review board approved each RCT protocol. All participants provided written informed consent prior to study assessments. Data are available from the authors upon reasonable request.

\section{Treatments}

Treatments were CBT, BWL, and combination or multi-modal treatments (i.e., CBT or BWL plus pharmacotherapy). Control conditions (i.e., double-blind trial with placebo or unguided self-help or inert attention-for-control condition) were also included in analyses. Treatments reflected the literature on psychological (Grilo, 2017b) and pharmacological (Reas \& Grilo, 2015) treatments for BED. Detailed descriptions of the RCTs have been published (Grilo, 2017a; Grilo, Masheb, \& Salant, 2005; Grilo et al., 2014; Grilo, Masheb, \& Wilson, 2005; Grilo et al., 2011; Grilo et al., 2013).

All treatment trials enrolled both men and women. Treatment durations ranged between 3 and 6 months, which generally parallels the broader literature on RCTs for BED (Grilo, 2017b; McElroy, 2017; National Institute for Health and Care Excellence, 2017; Reas \& Grilo, 2015). We standardized the amount of data contributed across protocols by including assessment time points in the aggregated data that occurred at baseline, one month into treatment, two months into treatment, and at post-treatment. All studies had independent outcome assessments performed by doctoral-level research evaluators who were blinded to both the medication and behavioral treatment status. Pharmacological studies were doubleblind; placebos were matched in number of pills and in appearance (i.e., visually identical to active medications).

Cognitive-Behavioral Therapy (CBT).-CBT followed manualized treatment developed initially by Fairburn, Marcus, and Wilson (1993), which has since been refined and supported by numerous RCTs for BED (e.g., Wilfley et al., 2002). Manualized CBT was administered by trained and monitored doctoral-level research-clinicians. CBT focuses on teaching specific behavioral strategies to help patients identify problematic eating patterns and make their eating more regular, such as self-monitoring and goal-setting, as well as 
identifying and modifying maladaptive cognitive processes. CBT has been highlighted as the treatment of choice for BED and is considered the best evidence-based psychological treatment for BED (National Institute for Health and Care Excellence, 2017). RCTs have supported CBT for BED in both full and guided self-help treatment modalities (National Institute for Health and Care Excellence, 2017; Wilson, Wilfley, Agras, \& Bryson, 2010; Wilson \& Zandberg, 2012).

Behavioral Weight Loss (BWL)._BWL followed the manualized treatment initially developed by Brownell (2000) as the LEARN Program for Weight Management. BWL has since been expanded and supported by several RCTs for BED (Devlin, Goldfein, Petkova, Liu, \& Walsh, 2007; Wilson et al., 2010) and obesity (Wadden et al., 2011). Manualized BWL was administered by trained and monitored doctoral-level research-clinicians. BWL focuses on making gradual behavioral lifestyle changes to nutrition and exercise through sustainable caloric restriction and increases in physical activity through strategies including collaborative goal setting, self-monitoring, and use of social support. Nutritional advice was consistent with federal recommendations.

Multi-Modal Treatment.-Multi-modal treatment included pharmacotherapy combined with BWL or CBT. Participants receiving medications were managed by study-physicians who were trained in study protocols for medication delivery and management of ongoing medication issues including adherence and side effects. Across studies, medications were sibutramine, orlistat, or fluoxetine, which have varied levels of support across studies as either mono- or combination-therapy for BED (McElroy, 2017; Reas \& Grilo, 2015). Sibutramine is a serotonin and norepinephrine reuptake inhibitor, with some evidence that it produces weight loss and improvements in binge eating (Appolinario et al., 2003; Wilfley et al., 2008). Orlistat is a lipase inhibitor that reduces dietary fat absorption, with some evidence that it produces weight loss (e.g., Davidson et al., 1999), including in patients with binge eating (Golay et al., 2005). Fluoxetine is a selective serotonin reuptake inhibitor with some initial evidence supporting its use in BED (Marcus et al., 1990).

Control Conditions.-In studies testing medications, the control treatment was placebo medication. Placebos were matched in number of pills and visually identical to the active medication. In studies with behavioral interventions, the control condition was either unguided self-help treatment or daily self-monitoring forms only. In unguided self-help treatments, patients were given a copy of a CBT book for binge eating (Fairburn, 1995) and were told to read the book and follow the self-help recommendations included in the text.

\section{Measures}

Research-clinicians administered the Structured Clinical Interview for DSM-IV Axis I Disorders (First, Spitzer, Gibbon, \& Williams, 1997) to determine the DSM-IV-based BED diagnosis and psychiatric comorbidities. Research-clinicians also administered the semistructured Eating Disorder Examination (EDE; Fairburn \& Cooper, 1993) to confirm BED diagnosis and characterize eating-disorder psychopathology. All research clinicians had doctoral-level training and additional training in these specific assessment instruments; all 
were supervised and monitored to maintain reliability and prevent drift. Each of the individual RCTs reported good inter-rater reliability for the EDE interview.

Percent Weight Loss.-Research-clinicians measured participants' weight to calculate percent weight loss (the difference between a later weight and the baseline weight, divided by the baseline weight; negative values indicate weight loss).

Eating Disorder Examination-Questionnaire (EDE-Q).-The EDE-Q is the selfreport version of the EDE Interview (Fairburn \& Beglin, 1994). The EDE-Q measures eating-disorder psychopathology over the prior 28 days, and also assesses objective bingeeating episodes (OBEs, eating an unusually large amount of food while perceiving a loss of control over eating; this corresponds to the $D S M$ definition of binge eating). The global severity score reflects eating-disorder psychopathology including eating concerns, weight and shape concerns, and dietary restraint. Among patients with BED, the EDE-Q has shown excellent test-retest reliability (Reas, Grilo, \& Masheb, 2006) and acceptable concordance with EDE interview (Grilo, Masheb, \& Wilson, 2001). Each of the individual RCTs reported excellent internal consistency for the global severity score.

Beck Depression Inventory (BDI).- - The BDI is a well-established and widely-used measure of depression that captures a broad range of negative affect (Beck \& Steer, 1987). The BDI has excellent psychometric properties (Beck, Steer, \& Carbin, 1988). Each of the individual RCTs reported excellent internal consistency values for the BDI.

\section{Statistical Analyses}

Analyses, which included all randomized participants with at least one post-baseline measure, compared men and women on treatment outcomes: binge-eating episodes both dimensionally (frequency) and categorically (remission), weight both dimensionally (percent loss) and categorically (attainment of 5\% loss), EDE-Q global severity score, and BDI depression score. Because treatments ranged from 3 to 6 months, analyses used all available data from baseline, month 1, month 2, and post-treatment. Descriptive statistics were evaluated prior to statistical analyses. Distributions of all outcome variables were examined: log-transformation was applied to binge-eating episode frequency and square-root transformation was applied to depression scores prior to analyses to meet assumptions of normality. "Remission" from binge eating was defined as zero episodes during the previous 28 days. For binge-eating remission and 5\% weight loss, analyses were performed with failure imputed for missing data and separately with all available data. Significance level of . 05 was used to evaluate all tests.

Mixed models (SAS PROC MIXED) examined quantitative outcome variables for men and women, making use of all available data. We used mixed model analysis rather than metaanalysis after careful consideration. The mixed model approach was also the preferred method used by earlier BED studies of aggregated data (Franko et al., 2012; ThompsonBrenner et al., 2013). Mixed models have well-established advantages for this type off study, particularly the application of consistent data analysis techniques across the studies (Cooper \& Patall, 2009; Curran \& Hussong, 2009). 
In the mixed models, fixed effects were sex (male and female), treatment group (BWL, CBT, Multi-Modal, and Control), time (baseline, month 1, month 2, and post) and all possible interactions. Baseline was not included in analyses of percent weight loss (as change is calculated from baseline values). For each model, different variance-covariance structures (unstructured [UN], compound symmetry [CS], compound symmetry heterogeneous [CSH] with and without a random effect for protocol) were evaluated and the best-fitting structure was selected based on Schwartz Bayesian criterion (BIC). Least square means were estimated from all models and compared as necessary to explain significant effects in the models.

The categorical binge eating remission variable was analyzed using a Generalized Estimating Equations model with binomial response distribution and logit link. Baseline values were not included in this analysis (as binge-eating episodes were required for eligibility). The categorical 5\% weight loss variable was analyzed using a generalized linear model with logit link and a binary response at the post time point.

\section{Results}

\section{Clinical Characteristics by Sex}

Table 1 summarizes the clinical characteristics of men and women with BED across treatment evaluation time points. Completed assessments and available data did not significantly differ between men and women at month 1 (men: $73.5 \%, n=125$, women: $80.4 \%, n=394$ ), and month 2 (men: $90.0 \%, n=153$, women $92.9 \%, n=455$ ). More women $(91.0 \%, n=446)$ than men $(82.4 \%, n=140)$ completed post-treatment assessments. All treatment conditions included both men and women: CBT (men: $21.8 \%, n=37$; women: 72.8\%, $n=133$ ), BWL (men: $27.3 \%, n=33$; women: $72.7 \%, n=88$ ), multi-modal (men: 29.7\%, $n=68$; women: $70.3 \%, n=161$ ), and control (men: $22.9 \%, n=32$; women: $77.1 \%$, $n=108$ ). The proportions of men and women did not significantly differ (all $p s>.05$ ) across treatment conditions.

\section{Binge Eating Frequency and Remission}

Figure 1 depicts binge eating frequency by sex, time, and treatment. The sex by treatment by time interaction was not significant, which indicates that sex did not significantly moderate treatment effects. Similarly, sex did not have a significant main effect, indicating that sex is not a predictor of treatment effects. There was a significant treatment by time interaction $\left(F_{9,624}=3.56, p<.001\right)$, and significant main effects of treatment $\left(F_{3,209}=4.11, p=.007\right)$ and time $\left(F_{3,595}=223.16, p<.0001\right)$. Post-hoc comparisons revealed that for both men and women, CBT $(p=.017)$ and multi-modal treatment $(p=.010)$ were associated with significant reductions in binge eating frequencies compared to control conditions. The reduction was greatest at post-treatment $(p<.0001)$, and also significant at month $2(p<.001)$.

When binge eating remission was examined, imputing failure for missing data, there was a significant time by treatment interaction $\left(\chi^{2}(6)=15.58, p=.016\right)$, and a significant main effect of time $\left(\chi^{2}(2)=59.83, p<.0001\right)$, but no sex or treatment effects were significant. Remission 
rates significantly increased over time with significant differences for all pairwise comparisons among time points.

When remission analyses were repeated using available data (i.e., using all enrolled patients without imputing missing data), there was a significant time by treatment interaction $\left(\chi^{2}(6)=20.11, p=.003\right)$, and significant main effects of treatment $\left(\chi^{2}(3)=9.25, p=.026\right)$ and time $\left(\chi^{2}(2)=57.62, p<.0001\right)$. Remission rates significantly increased over time with significant differences for all pairwise comparisons among time points. BWL, CBT, and multi-modal treatments all produced greater remission rates than control conditions. There were no significant sex effects. Figure 2 depicts binge eating remission by sex, time, and treatment.

\section{Percent Weight Loss}

Figure 3 depicts percent weight loss by sex, time, and treatment. There was a significant sex by time interaction $\left(F_{2,540}=6.59, p=.002\right)$ : men had significantly greater reductions in percent weight loss at month $2(p=.04)$ and post-treatment $(p=.002)$ across treatments. There was also a significant treatment by time interaction $\left(F_{6,528}=8.69, p<.0001\right)$ : for both men and women, treatment differences were evident at all time points but were more pronounced at month 2 and post-treatment. In addition, there was a significant main effect of sex $\left(F_{1,581}=5.41, \mathrm{p}=.02\right)$, such that men had a greater percent weight loss than women. There was also a significant main effect of time $\left(F_{2,531}=51.32, p<.0001\right)$, such that there was greater weight loss over time. Treatments also produced significantly different percent weight loss $\left(F_{3,330}=15.63, p<.0001\right)$ : the best treatments for percent weight loss were BWL and multi-modal treatment, but CBT and control conditions did not lead to significant percent weight loss.

Weight change was also examined categorically at the post time point, comparing men and women enrolled in different treatments on whether they achieved 5\% weight loss; these analyses imputed failure for missing data. Sex had a significant main effect, $\chi^{2}(1)=4.08, p=$. 043), as did treatment, $\chi^{2}(3)=63.87, p<.0001$, but the interaction of sex and treatment was not significant. BWL and multi-modal treatments were more likely to produce $5 \%$ weight loss than CBT and control conditions.

When 5\% weight loss analyses were repeated using all available data without imputation, the pattern of results remained unchanged. Sex had a main effect, $\chi^{2}(1)=3.84, p=.05$, and treatment, $\chi^{2}(3)=62.54, p<.0001$, but the interaction of sex and treatment was not significant. BWL and multi-modal treatments were more likely to produce $5 \%$ weight loss than CBT and control conditions. Figure 4 depicts $5 \%$ weight loss by sex and treatment at post.

\section{Eating-Disorder Psychopathology}

There was a significant main effect of sex on eating-disorder psychopathology $\left(F_{1,661}=16.59, p<.0001\right)$. Men had lower eating-disorder psychopathology than women across all treatments and time points. There was also a significant treatment by time interaction $\left(F_{9,615}=2.41, p=0.01\right)$ and a significant main effect of time $\left(F_{3,594}=102.51, \mathrm{p}<\right.$. 
0001). Post-hoc comparisons revealed that eating-disorder psychopathology decreased over time but there were no significant differences among treatments at each time point.

\section{Depression}

Interactions among sex, treatment, and time were all not significant. There was a significant main effect of time $\left(F_{3,597}=100.37, p<.0001\right)$. Depression scores significantly decreased over time; only the difference between scores at months 1 and 2 did not significantly differ. There were no significant differences by sex.

\section{Discussion}

The current study examined sex differences in treatment outcomes among men and women with BED in data aggregated from RCTs testing psychological and pharmacological treatments-including CBT, BWL, multi-modal treatments, and control conditions-for BED. Overall, sex did not moderate any treatment effects but did emerge as a significant predictor for a few treatment outcomes. Men achieved greater weight loss, both dimensionally and categorically, than women over the course of treatment, and men had lower levels of eating-disorder psychopathology than women across all time points. No additional significant associations of sex with treatment effects were observed: men and women had similar frequencies and reductions in binge-eating episodes, rates of bingeeating remission, and similar reductions in depression. These findings indicate, as we reported previously when characterizing baseline characteristics (Lydecker \& Grilo, 2018), and as reported in aggregated psychological treatment data analyses by Shingleton et al (2015), that although there are some differences in the clinical presentation of men and women seeking treatment for BED, the magnitude and patterns of outcomes do not suggest the need for different treatments for men and women.

As context for the findings related to sex differences in treatment outcomes for BED, we also note that our aggregated treatment findings confirm earlier work by other groups that has shown differences in important treatment outcomes (binge eating and weight loss) by the type of treatment provided. CBT and multi-modal treatment produced significantly greater reductions in binge-eating episodes than control conditions, as has been reported for CBT combined with topiramate (Claudino et al., 2007), and there was significantly greater weight loss in BWL than CBT (Wilson et al., 2010). Importantly, our study adds new findings about sex as a predictor of weight loss among patients receiving treatment for BED. We found that men with BED lost more weight and were more likely to lose $5 \%$ of their starting weight than women with BED. Significant sex differences in weight loss are consistent with findings from the obesity and diabetes treatment literature (e.g., the Look AHEAD study; Wadden et al., 2009). Men with BED's higher weight at baseline, and their greater percent weight loss over the course of treatment compared to women with BED, suggests that although men might have a marginally greater risk for obesity-related health problems before beginning treatment, treatment can improve their weight. Future research should examine potential mechanisms through which these sex differences might occur, for example, if levels of internalized weight bias differ significantly. 
Our findings about eating-disorder psychopathology and binge eating are largely consistent with findings from early work derived from data pooled from psychological treatments conducted at various research sites (Shingleton et al., 2015). However, whereas Shingleton et al (2015) found that sex did not predict treatment outcomes, we found a main effect that men had lower eating-disorder psychopathology over the course of treatment. As with baseline sex differences reported previously (Lydecker \& Grilo, 2018), the magnitude of the difference in global eating-disorder psychopathology scores between men and women was small. Importantly, our study examined sex differences across different treatments - CBT, BWL, multi-modal treatment and control conditions - across multiple time points. Our finding that sex did not moderate treatment outcomes across this broad and clinicallyrelevant range of treatment methods is important because it suggests that men and women may benefit similarly from varied treatment approaches.

Collectively, our findings considered together with those from Shingleton et al (2015) suggest that men and women with BED have generally similar responses to treatment. Thus, although epidemiological studies have found that men are less likely to seek treatment for BED than women (Coffino et al., 2019), and are underrepresented in clinical trials (National Institues of Health, 2018), our findings here suggest that men appear to benefit from BWL, CBT, and multi-modal treatments to a similar (for binge eating) or better (for weight loss) extent than women. These findings are encouraging for the broader dissemination of these treatments to clinicians working with women and men with BED. Unfortunately, the failure to identify moderators means that our data cannot help clinicians make specific treatment recommendations to their patients based on their sex. Thus, the best approach may be to describe the available evidence-based treatment approaches along with their expected outcomes and to engage patients in selecting one that they think fits their needs and preferences. Additional research should examine whether there are predictors or moderators of longer-term outcomes (maintenance, relapse) during post-treatment follow-up periods.

In addition to findings from individual RCTs, findings from our study and from the study by Shingleton et al (2015) should be considered in conjunction with each other. Our study and the study by Shingleton et al (2015) had similar sample sizes of men ( $n=208$ and $n=170$ ). Our findings pertain to treatment-seeking individuals with BED who received various treatments at a northeastern US medical school, delivered in the context of research, and the study by Shingleton et al (2015) aggregated psychological treatment data from varied geographical regions. Methodologically, whereas data aggregated across sites may have systematic error variance due to geographical or site-specific differences, our study design allowed us to reduce such potential confounds. Trials at our site used consistent study protocols, including procedures for recruitment, eligibility determination, screening and assessment, and clinician training and supervision.

Despite the strengths our study offers, there are limitations. Our findings pertain to men and women with BED who chose to participate in treatment studies for BED. Whether the same patterns of sex differences apply to individuals who seek treatment in different clinical settings (Marques et al., 2011), those who do not seek treatment, or those who do not wish to participate in treatment research is uncertain. In addition, randomization was performed within each treatment trial, and data were aggregated across studies for the current analyses. 
Treatments within the aggregated treatment condition categories considered in this study had some variability across trials; thus, it is possible that the findings may have differed if treatments (e.g., versions of CBT or BWL, or specific medications) and control condition were more uniform, although uniformity would also have limited generalizability. Additionally, we analyzed sex differences and although sex is in many ways similar to the social construct of gender, gender identity may yield more nuanced information about adults seeking BED treatment. Our studies had some exclusion criteria, primarily safety-based, and most participants were White and highly educated. Thus, findings might not generalize to the important groups not well-represented in our sample.

Sex differences - and lack of differences - in treatment outcomes among individuals with BED are important for clinicians and clinical researchers to understand as they may help refine treatment selection and delivery. The findings that there are minimal differences in treatment outcomes between men and women with BED suggest that the evaluated treatments can be disseminated more broadly, which is encouraging given the particular need for treatment for men with BED (Coffino et al., 2019). Continued research is needed to improve knowledge about specific treatment-related needs across diverse patient groups, whether other demographic and clinical factors predict and/or moderate treatment outcomes, and especially to understand the mechanisms by which treatments may work, which is needed to refine the interventions further.

\section{Acknowledgments}

Funding: This research was supported, in part, by National Institutes of Health grants K24 DK070052 and R01 DK49587, American Heart Association, and Donaghue Medical Research Foundation. Drs. Grilo, Lydecker and Gueorguieva were supported, in part, by National Institutes of Health grants K23 DK115893, R01 DK112771, R01 DK49587 and R01 DK114075. This paper does not reflect the views of the Public Health Service, NIH, AHA, nor the Donaghue Medical Research Foundation; funders played no role in the content of this paper.

\section{References}

American Psychiatric Association. (2004). Diagnostic and Statistical Manual of Mental Disorders (Fourth, Text Revision ed.). Washington, DC: Author.

American Psychiatric Association. (2013). Diagnostic and Statistical Manual of Mental Disorders (5th ed). Arlington, VA: American Psychiatric Publishing.

Appolinario JC, Bacaltchuk J, Sichieri R, Claudino AM, Godoy-Matos A, Morgan C, ... Coutinho W. (2003). A randomized, double-blind, placebo-controlled study of sibutramine in the treatment of binge-eating disorder. Archives of General Psychiatry, 60, 1109-1116. doi: 10.1001/archpsyc. 60.11.1109 [PubMed: 14609886]

Beck AT, \& Steer R (1987). Manual for revised Beck Depression Inventory. New York: Psychological Corporation.

Beck AT, Steer RA, \& Carbin MG (1988). Psychometric properties of the Beck Depression Inventory: Twenty-five years of evaluation. Clinical Psychology Review, 8, 77-100.

Brownell KD (2000). The LEARN program for weight management. Dallas American Health Publishing.

Claudino AM, de Oliveira IR, Appolinario JC, Cordas TA, Duchesne M, Sichieri R, \& Bacaltchuk J (2007). Double-blind, randomized, placebo-controlled trial of topiramate plus cognitive-behavior therapy in binge-eating disorder. Journal of Clinical Psychiatry, 68, 1324-1332. [PubMed: 17915969] 
Coffino JA, Udo T, \& Grilo CM (2019). Rates of Help-seeking in U.S. adults with Lifetime DSM-5 Eating Disorders: Prevalence Across Diagnoses and Sex and Ethnic/Racial Differences. Mayo Clinic Proceedings.

Cooper H, \& Patall EA (2009). The relative benefits of meta-analysis conducted with individual participant data versus aggregated data. 14, 165-176. doi: 10.1037/a0015565

Curran PJ, \& Hussong AM (2009). Integrative data analysis: the simultaneous analysis of multiple data sets. 14, 81-100. doi: 10.1037/a0015914

Davidson MH, Hauptman J, DiGirolamo M, Foreyt JP, Halsted CH, Heber D, ... Heymsfield SB. (1999). Weight control and risk factor reduction in obese subjects treated for 2 years with orlistat: a randomized controlled trial. Journal of the American Medical Association, 281, 235-242. [PubMed: 9918478]

Devlin MJ, Goldfein JA, Petkova E, Liu L, \& Walsh BT (2007). Cognitive behavioral therapy and fluoxetine for binge eating disorder: Two-year follow-up. Obesity, 15, 1702-1709. doi: 10.1038/ oby.2007.203 [PubMed: 17636088]

Fairburn CG (1995). Overcoming Binge Eating. New York Guilford Press.

Fairburn CG, \& Beglin S (1994). Assessment of eating disorders: Interview or self-report questionnaire? International Journal of Eating Disorders, 16, 363-370. [PubMed: 7866415]

Fairburn CG, \& Cooper Z (1993). The Eating Disorder Examination In Fairburn CG \& Wilson GT (Eds.), Binge Eating: Nature, Assessment, and Treatment (pp. 317-360). New York: Guilford Press.

Fairburn CG, Marcus MD, \& Wilson GT (1993). Cognitive-behavioral therapy for binge eating and bulimia nervosa: A comprehensive treatment manual In Fairburn CG \& Wilson GT (Eds.), Binge Eating: Nature, Assessment, and Treatment (pp. 361-404). New York Guilford Press.

First MB, Spitzer RL, Gibbon M, \& Williams JBW (1997). Structured Clinical Interview for DSM-IV Axis I Disorders (SCID-I), Clinician Version. Washington, DC: American Psychiatric Press.

Franko DL, Thompson-Brenner H, Thompson DR, Boisseau CL, Davis A, Forbush KT, ... Wilson GT. (2012). Racial/ethnic differences in adults in randomized clinical trials of binge eating disorder. Journal of Consulting and Clinical Psychology, 80, 186-195. doi: 10.1037/a0026700 [PubMed: 22201327]

Golay A, Laurent-Jaccard A, Habicht F, Gachoud JP, Chabloz M, Kammer A, \& Schutz Y (2005). Effect of orlistat in obese patients with binge eating disorder. Obesity Research, 13, 1701-1708. doi: 10.1038/oby.2005.208 [PubMed: 16286517]

Goldstein DJ (1992). Beneficial health effects of modest weight loss. International Journal of Obesity and Related Metabolic Disorders, 16, 397-415. [PubMed: 1322866]

Grilo CM (2017a). Behavioral weight loss vs stepped multi-modal treatment for binge eating disorder: Acute and longer-term 18-month outcomes. Annals of Behavioral Medicine, 51, S752-S753.

Grilo CM (2017b). Psychological and behavioral treatments for binge-eating disorder. Journal of Clinical Psychiatry, 78 Suppl 1, 20-24. doi: 10.4088/JCP.sh16003su1c.04 [PubMed: 28125175]

Grilo CM, \& Masheb RM (2005). A randomized controlled comparison of guided self-help cognitive behavioral therapy and behavioral weight loss for binge eating disorder. Behaviour Research and Therapy, 43, 1509-1525. doi: 10.1016/j.brat.2004.11.010 [PubMed: 16159592]

Grilo CM, Masheb RM, \& Salant SL (2005). Cognitive behavioral therapy guided self-help and orlistat for the treatment of binge eating disorder: A randomized, double-blind, placebo-controlled trial. Biological Psychiatry, 57, 1193-1201. [PubMed: 15866560]

Grilo CM, Masheb RM, White MA, Gueorguieva R, Barnes RD, Walsh BT, ... Garcia R. (2014). Treatment of binge eating disorder in racially and ethnically diverse obese patients in primary care: Randomized placebo-controlled clinical trial of self-help and medication. Behaviour Research and Therapy, 58, 1-9. doi: 10.1016/j.brat.2014.04.002 [PubMed: 24857821]

Grilo CM, Masheb RM, \& Wilson GT (2001). A comparison of different methods for assessing the features of eating disorders in patients with binge eating disorder. Journal of Consulting and Clinical Psychology, 69, 317-322. [PubMed: 11393608]

Grilo CM, Masheb RM, \& Wilson GT (2005). Efficacy of cognitive behavioral therapy and fluoxetine for the treatment of binge eating disorder: A randomized double-blind placebo-controlled comparison. Biological Psychiatry, 57, 301-309. [PubMed: 15691532] 
Grilo CM, Masheb RM, Wilson GT, Gueorguieva R, \& White MA (2011). Cognitive-behavioral therapy, behavioral weight loss, and sequential treatment for obese patients with binge-eating disorder: A randomized controlled trial. Journal of Consulting and Clinical Psychology, 79, 675685. doi: 10.1037/a0025049 [PubMed: 21859185]

Grilo CM, Reas DL, \& Mitchell JE (2016). Combining pharmacological and psychological treatments for binge eating disorder: Current status, limitations, and future directions. Curr Psychiatry Rep, 18, 1-11. doi: 10.1007/s11920-016-0696-z [PubMed: 26685903]

Grilo CM, White MA, Gueorguieva R, Barnes RD, \& Masheb RM (2013). Self-help for binge eating disorder in primary care: A randomized controlled trial with ethnically and racially diverse obese patients. Behaviour Research and Therapy, 51, 855-861. doi: 10.1016/j.brat.2013.10.002 [PubMed: 24189569]

Hilbert A, Petroff D, Herpertz S, Pietrowsky R, Tuschen-Caffier B, Vocks S, \& Schmidt R (2019). Meta-analysis of the efficacy of psychological and medical treatments for binge-eating disorder. 87, 91-105. doi: 10.1037/ccp0000358

Kraemer HC, Wilson GT, Fairburn CG, \& Agras WS (2002). Mediators and moderators of treatment effects in randomized clinical trials. Archives of General Psychiatry, 59, 877-883. [PubMed: 12365874]

Lydecker JA, \& Grilo CM (2018). Comparing men and women with binge-eating disorder and comorbid obesity. International Journal of Eating Disorders, 51, 411-417. doi: 10.1002/eat.22847 [PubMed: 29493793]

Marcus MD, Wing RR, Ewing L, Kern E, McDermott M, \& Gooding W (1990). A double-blind, placebo-controlled trial of fluoxetine plus behavior modification in the treatment of obese bingeeaters and non-binge-eaters. American Journal of Psychiatry, 147, 876-881. doi: 10.1176/ajp. 147.7.876 [PubMed: 2192563]

Marques L, Alegria M, Becker AE, Chen CN, Fang A, Chosak A, \& Diniz JB (2011). Comparative prevalence, correlates of impairment, and service utilization for eating disorders across US ethnic groups: Implications for reducing ethnic disparities in health care access for eating disorders. International Journal of Eating Disorders, 44, 412-420. doi: 10.1002/eat.20787 [PubMed: 20665700]

McElroy SL (2017). Pharmacologic Treatments for Binge-Eating Disorder. Journal of Clinical Psychiatry, 78 Suppl 1, 14-19. doi: 10.4088/JCP.sh16003su1c.03 [PubMed: 28125174]

National Institues of Health. (2018). NIH RCDC Inclusion Statistics Report. Washington, D. C.: Author Retrieved from https://report.nih.gov/RISR/\#/.

National Institute for Health and Care Excellence. (2017). Eating disorders: recognition and treatment NICE Guideline (NG69).

Reas DL, \& Grilo CM (2015). Pharmacological treatment of binge eating disorder: update review and synthesis. Expert Opinion in Pharmacotherapy, 16, 1463-1478. doi: 10.1517/14656566.2015.1053465

Reas DL, Grilo CM, \& Masheb RM (2006). Reliability of the Eating Disorder ExaminationQuestionnaire in patients with binge eating disorder. Behaviour Research and Therapy, 44, 43-51. doi: 10.1016/j.brat.2005.01.004 [PubMed: 16301013]

Shingleton RM, Thompson-Brenner H, Thompson DR, Pratt EM, \& Franko DL (2015). Gender differences in clinical trials of binge eating disorder: An analysis of aggregated data. Journal of Consulting and Clinical Psychology, 83, 382-386. doi: 10.1037/a0038849 [PubMed: 25730521]

Striegel RH, Bedrosian R, Wang C, \& Schwartz S (2012). Why men should be included in research on binge eating: Results from a comparison of psychosocial impairment in men and women. International Journal of Eating Disorders, 45, 233-240. doi: 10.1002/eat.20962 [PubMed: 22031213]

Thompson-Brenner H, Franko DL, Thompson DR, Grilo CM, Boisseau CL, Roehrig JP, ... Wilson GT. (2013). Race/ethnicity, education, and treatment parameters as moderators and predictors of outcome in binge eating disorder. Journal of Consulting and Clinical Psychology, 81, 710-721. doi: 10.1037/a0032946 [PubMed: 23647283] 
Udo T, \& Grilo CM (2018). Prevalence and correlates of DSM-5-defined eating disorders in a nationally representative sample of US adults. Biological Psychiatry, 84, 345-354. doi: 10.1016/ j.biopsych.2018.03.014 [PubMed: 29859631]

Udo T, \& Grilo CM (2019). Psychiatric and medical correlates of DSM-5 eating disorders in a nationally representative sample of adults in the United States. International Journal of Eating Disorders, 52, 42-50. doi: 10.1002/eat.23004 [PubMed: 30756422]

Wadden TA, Foreyt JP, Foster GD, Hill JO, Klein S, O’Neil PM, ... Dunayevich E. (2011). Weight loss with naltrexone SR/bupropion SR combination therapy as an adjunct to behavior modification: the COR-BMOD trial. Obesity, 19, 110-120. doi: 10.1038/oby.2010.147 [PubMed: 20559296]

Wadden TA, West DS, Neiberg RH, Wing RR, Ryan DH, Johnson KC, ... Look ARG. (2009). Oneyear weight losses in the Look AHEAD study: factors associated with success. 17, 713-722. doi: 10.1038/oby.2008.637

Wilfley DE, Crow SJ, Hudson JI, Mitchell JE, Berkowitz RI, Blakesley V, \& Walsh BT (2008). Efficacy of sibutramine for the treatment of binge eating disorder: a randomized multicenter placebo-controlled double-blind study. American Journal of Psychiatry, 165, 51-58. doi: 10.1176/ appi.ajp.2007.06121970 [PubMed: 18056225]

Wilfley DE, Welch RR, Stein RI, Spurrell EB, Cohen LR, Saelens BE, ... Matt GE. (2002). A randomized comparison of group cognitive-behavioral therapy and group interpersonal psychotherapy for the treatment of overweight individuals with binge-eating disorder. Archives of General Psychiatry, 59, 713-721. [PubMed: 12150647]

Wilson GT, Grilo CM, \& Vitousek KM (2007). Psychological treatment of eating disorders. American Psychologist, 62, 199-216. doi: 10.1037/0003-066x.62.3.199 [PubMed: 17469898]

Wilson GT, Wilfley DE, Agras WS, \& Bryson SW (2010). Psychological treatments of binge eating disorder. Archives of General Psychiatry, 67, 94-101. doi: 10.1001/archgenpsychiatry.2009.170 [PubMed: 20048227]

Wilson GT, \& Zandberg LJ (2012). Cognitive-behavioral guided self-help for eating disorders: effectiveness and scalability. Clinical Psychology Review, 32, 343-357. doi: 10.1016/j.cpr. 2012.03.001 [PubMed: 22504491] 

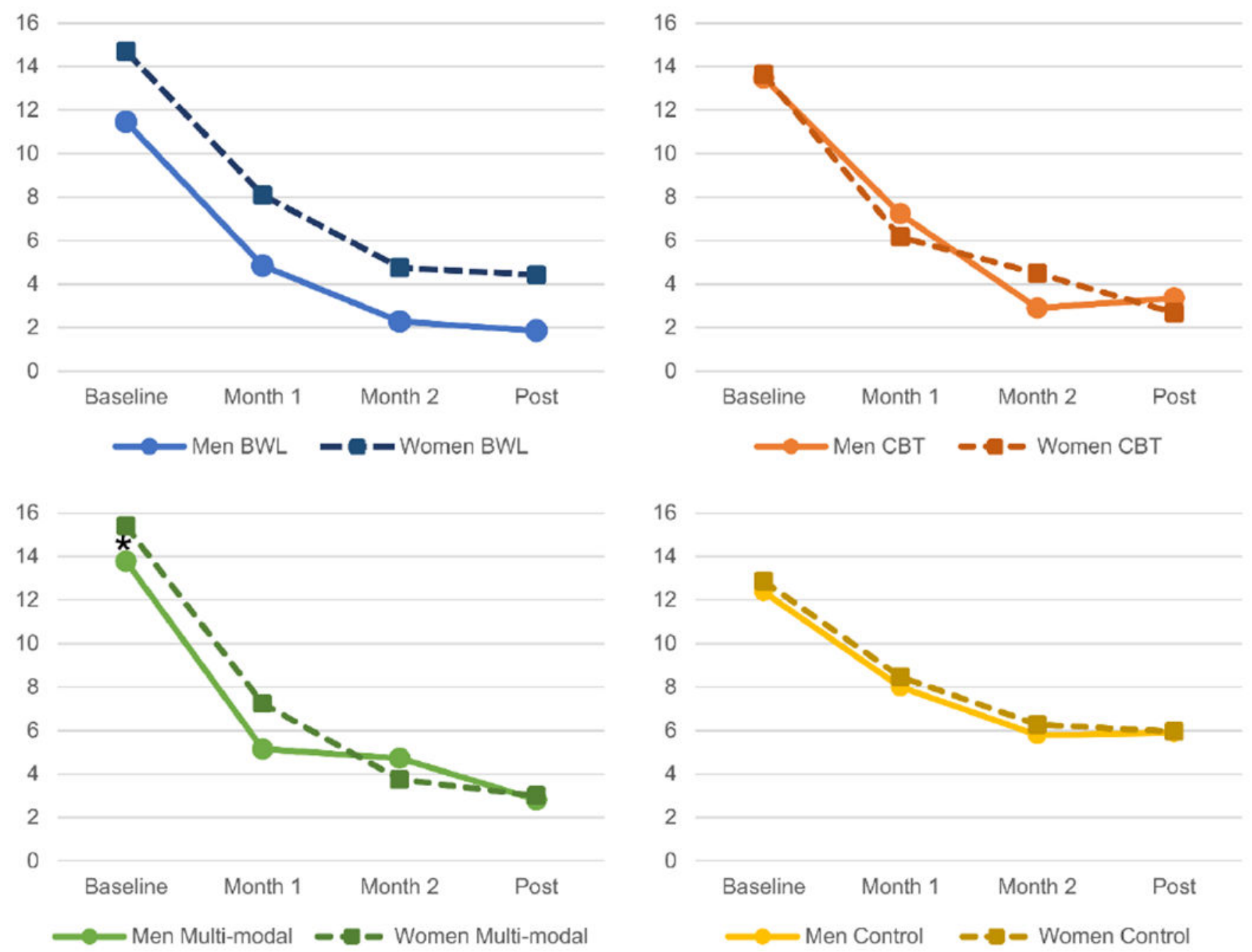

Figure 1.

Binge-Eating Episodes by Sex, Treatment, and Time

* Significant difference between men and women, $\mathrm{p}<.05$; omitted asterisks indicate nonsignificant difference between men and women. 


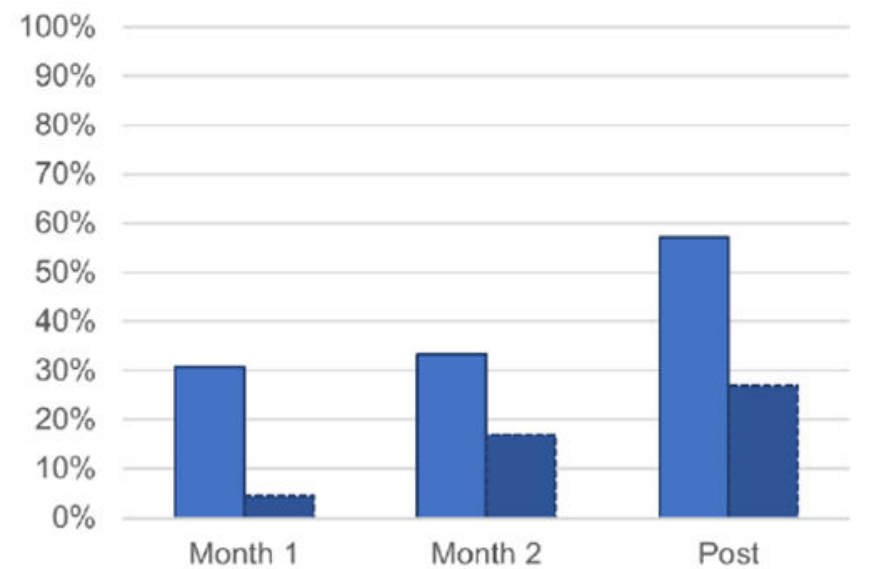

aMen BWL $\approx$ Women BWL

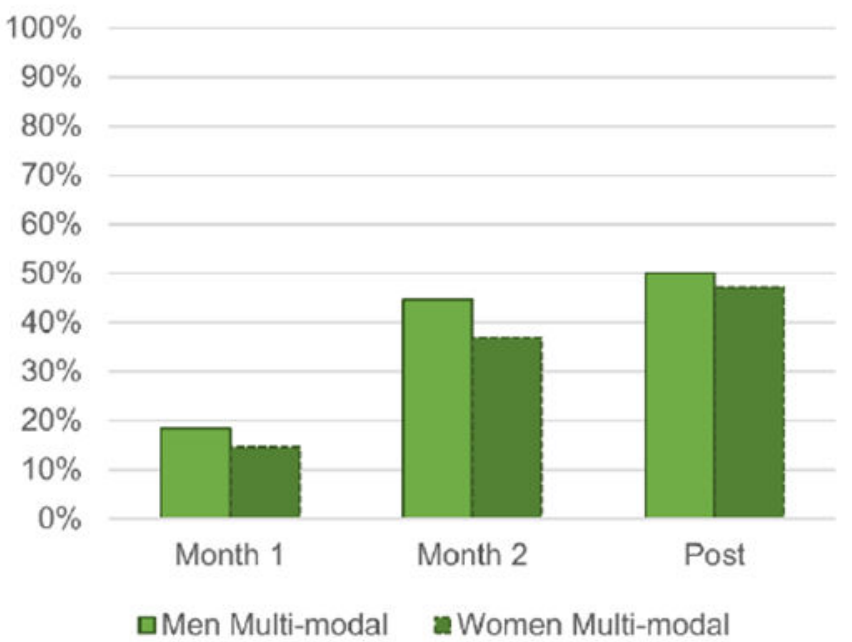

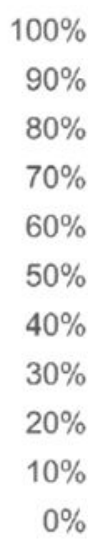

Figure 2.

Binge Eating Remission by Sex, Treatment, and Time significant difference between men and women.

$$
\begin{array}{r}
90 \% \\
80 \% \\
70 \% \\
60 \% \\
50 \% \\
40 \% \\
30 \% \\
20 \% \\
10 \% \\
0 \%
\end{array}
$$$$
100 \%
$$

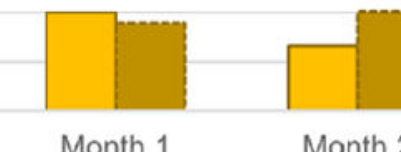

Month 2

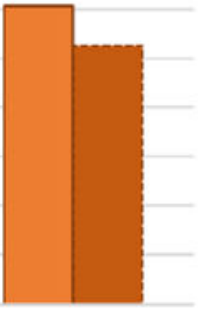

Post

aMen CBT aWomen CBT

\section{口Men Control aWomen Control}

* Significant difference between men and women, $\mathrm{p}<.05$; omitted asterisks indicate non- 

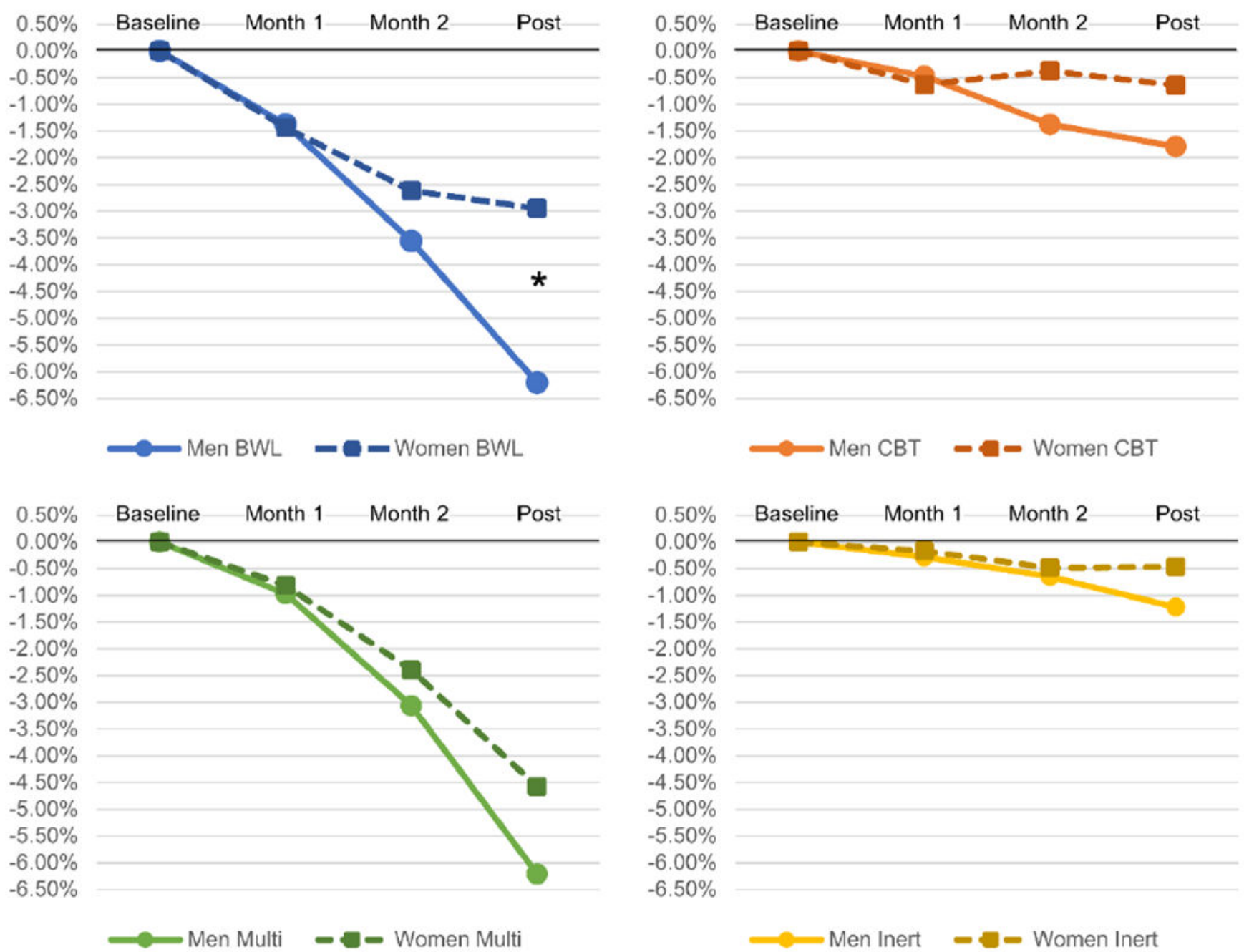

Figure 3.

Percent Weight Loss by Sex, Treatment, and Time

* Significant difference between men and women, $\mathrm{p}<.05$; omitted asterisks indicate nonsignificant difference between men and women. 
$60 \%$

$50 \%$

$30 \%$

$40 \%$

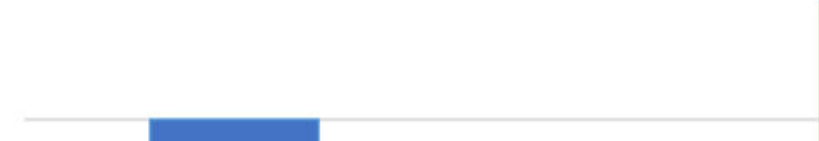
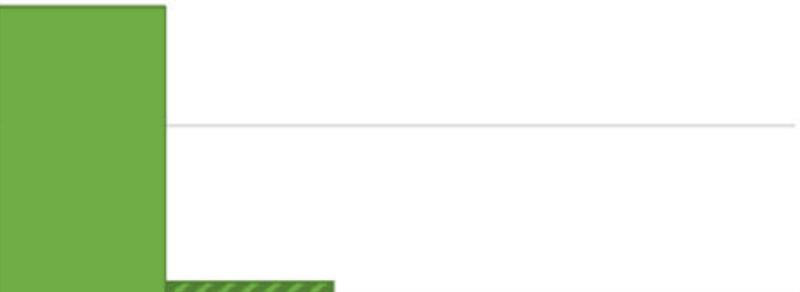

$20 \%$

$10 \%$

$0 \%$

\section{Post}

- Men BWL

- Women BWL

amen CBT

$\square$ Men Multi-modal

$\checkmark$ Women Multi-modal $\square$ Men Control

\section{Women CBT \\ Women Control}

Figure 4.

Attainment of 5\% Weight Loss by Sex and Treatment at Post

* Significant difference between men and women, $\mathrm{p}<.05$; omitted asterisks indicate nonsignificant difference between men and women. 


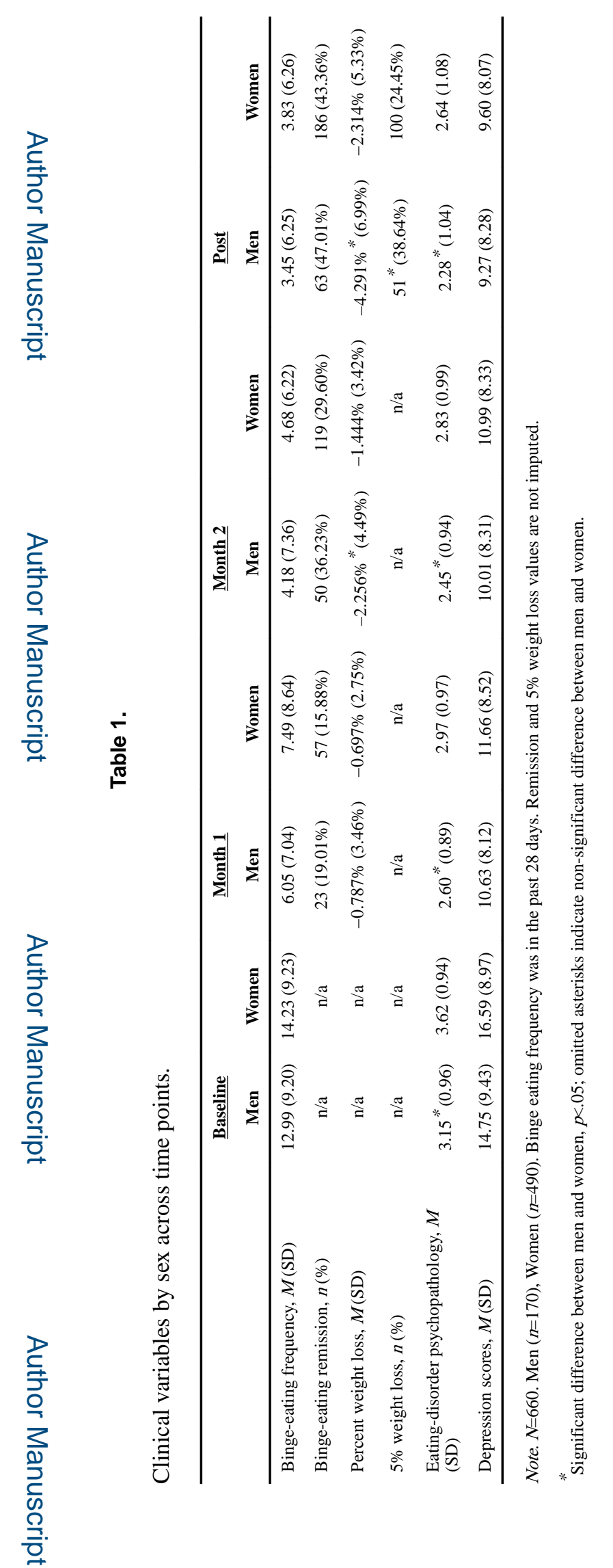

Int J Eat Disord. Author manuscript; available in PMC 2021 January 01. 